\title{
Penile Cancer and Syphilis: Report of Two Cases
}

\section{Vladimer Papava ${ }^{1}$, Shalva Chovelidze $^{2}$, D.Khochiashvili ${ }^{3}$, V. Kvakhajelidze ${ }^{4}$, Omar Khardzeishvili $^{5}$ Leli Sanidze ${ }^{6}$, Tamar Didbaridze ${ }^{7}$}

${ }^{1}$ TSMU Department of Urology, Assistant-Professor. MD, PhD (Tbilisi, Georgia).

${ }^{2}$ High Technology Medical Center, University Clinic Urology Department, MD, PhD (Tbilisi, Georgia)

${ }^{3}$ Head of Department of Urology, TSMU Professor. MD. PhD (Tbilisi, Georgia).

${ }^{4}$ Urologist. TSMU the First University Clinic.MD (Tbilisi, Georgia).

${ }^{5}$ Anatomical Pathology Department, TSMU Professor (Tbilisi, Georgia)

${ }^{6}$ Manager of the Georgian-Austrian Medical Centre, Lab Doctor, MD (Tbilisi, Georgia).

${ }^{7}$ TSMU Department of Microbiology, Associated -Professor, MD, PhD (Tbilisi, Georgia). vld100@inbox.ru

*Corresponding Author: Vladimer Papava, TSMU Department of Urology, Assistant-Professor. MD, PhD Tbilisi, Georgia.

\section{Abstract}

Until recently, syphilis was considered a major cause of penis cancer. Penile cancer is an extremely rare form of urological cancer that usually originates in the epithelium of the inner preputium or glans. The diagnosis of the condition is frequently delayed, and the disease and its treatment frequently result in significant morbidity in patients. Major etiological factors include phimosis, poor penile hygiene and smoking. Nearly 95\% of penile cancers are squamous cell carcinomas and usually occur in the sixth decade of life. The disease exhibits two variants, namely metastatic and atypical disease. Squamous differentiation may also present with mucinous metaplasia. An extremely limited number of case reports on penile cancer and syphilis are available in the literature. Penile cancer is an uncommon disease affecting only about one in 100,000 men worldwide annually. (1) While penile cancer often refers to squamous cell carcinomas (SCCs) of the penis in the literature, the term has also been used to describe nonsquamous penile malignant neoplasms. This lesion has been associated with invasive squamous cell carcinoma; however, metastasis without an invasive component is extremely rare. We report a two case in which syphilisi and penile cancer were diagnosed at presentation.

Keywords: syphilis, cancer, male, squamous cell

\section{INTRODUCTION}

Penile cancer is an extremely rare form of urological cancer that usually originates in the epithelium of the inner preputium or glans (1). Predisposing factors for penile cancer include chronic inflammatory diseases, such as phimosis, balanoposthitis and balanitis xerotica obliterans, ultraviolet phototherapy, multiple sexual partners, an early age at first intercourse and a previous history of condyloma (2). The lesions are often confined to the glans. Luciano [6] in Brazil, found $73 \%$ of lesions localized to the glans and foreskin. Squamous cell carcinoma is encountered the main histological type (3). Smoking and intercourse with a partner infected with human papilloma virus (HPV) types $6,11,16$ or 18 are also among the risk $95 \%$ of penile cancers are squamous cell carcinomas and usually occur in the sixth decade of life. The disease exhibits two variants, namely metastatic and atypical disease. Squamous differentiation may also present with mucinous metaplasia. An extremely limited number of case reports on penile cancer are available in the literature. Penile cancer is an uncommon disease affecting only about one in 100,000 men worldwide annually (4). While penile cancer often refers to squamous cell carcinomas (SCCs) of the penis in the literature, the term has also been used to describe nonsquamous penile malignant neoplasms. This lesion has been associated with invasive squamous cell carcinoma(SCC); however, metastasis without an invasive component is extremely rare(5). 
Penis cancer appears as a small lesion that extends gradually to affect the whole of the glans and the shaft of the penis. Until recently, syphilis was considered a major cause of penis cancer. Accurate histological diagnosis and staging of both the primary tumour and regional nodes are of utmost importance for selecting appropriate therapy(6).

Penile SCC most commonly presents between the ages of 50 and 70 years.The majority of lesions are found on the glans (48\%), followed by the prepuce (21\%), both glans and prepuce (15\%), coronal sulcus $(6 \%)$, and shaft $(<2 \%)$ (7). Clinical presentation is variable. It may present as a small area of induration and erythema or a large ulcerating and infiltrative lesion. As the disease progresses, there may be associated itching, bleeding, discharge, foul odor, and pain. $\frac{3}{\text { Presentation may be delayed secondary to }}$ psychological factors, with an estimated 15 to $60 \%$ of patients postponing presentation for at least one year(8).Despite this, most men (66\%) initially present with localized disease. ${ }^{4}$ Assessment of lymphatic spread with palpation of inguinal lymph nodes is an essential component of the initial physical exam. Lymphatic spread usually occurs in a predictable course, first to the superficial and deep inguinal nodes, followed by the pelvic, and then periaortic nodes. ${ }^{15}$ Distant metastases are generally uncommon (1-10\%) and occur late in the disease(9).

\section{CASE REPORT}

We describe 2 cases of penile cancer and syphilis that presented between 2007- 2016.

\section{Case 1}

A 62 year old male patient T.P. was present with the complaint of the lesion on the glanse which was present for the last 5-6 months. From time to time lesion was increasing in size. After physical examination 5-6 cm ulcerative excrescence was detected on the ventral surface of foreskin and glans.

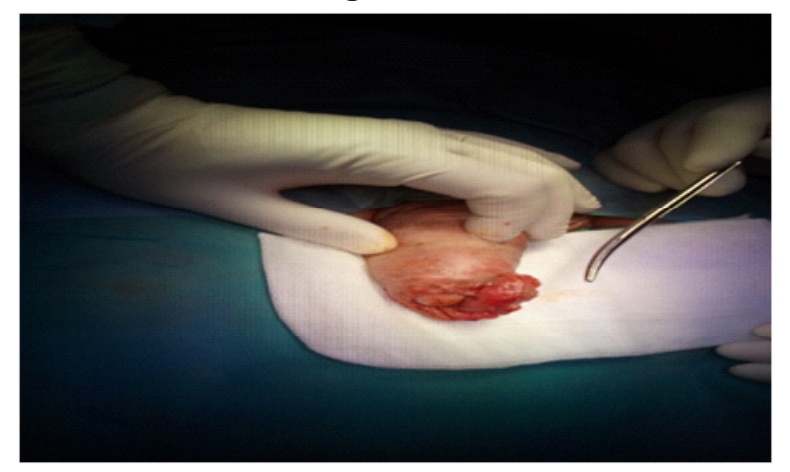

Picture 1
Diagnosis of syphilis was confirmed and treatment with Retarpen (benzathine benzylpenicillin) was conducted. Following analyses were done: small pelvis CT, MRI and histomorphological research. CT of small pelvis revealed $8 \mathrm{~mm}$ lymph nodules located on the external blood vessels of the distal part of right pelvis. Oval $1.5 \mathrm{~cm}$ long lymph nodes with hilar fat where detected. $9 \mathrm{~mm}$ lymph node with hypodense structure was present on the left inguinal. Histomorphological research revealed granulomatous inflammation with giant multinuclear cells.

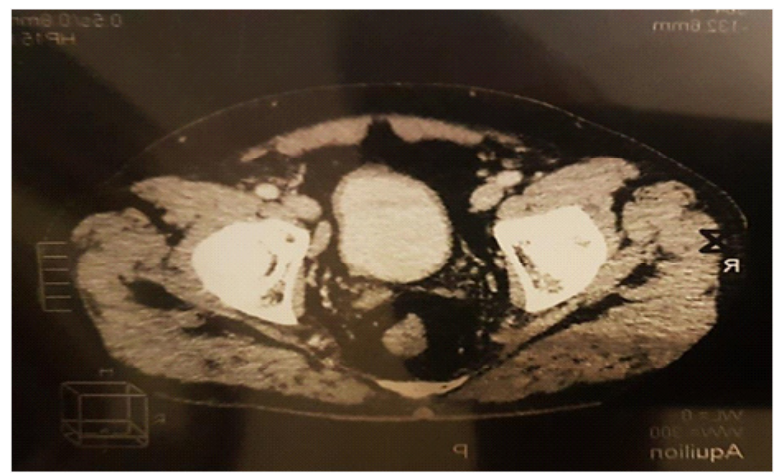

Picture 2

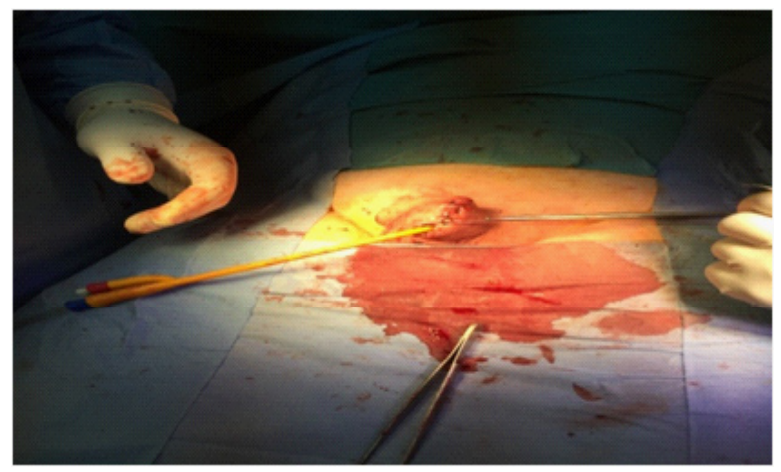

Picture 3

As the patient was in active syphilis stage, elective surgery was scheduled four weeks after treating syphilis. CT was conducted on repetitive manner (CT) where enlarged lymph nodules returned to normal size. That's why lymphadenectomy was taken out from the list of procedures. Ventral penile amputation was performed, as well as total resection of cavernosal bodies, includingdeepfascia of peniswith conglomerate of penile foreskin. After surgery, it wasrecommended to have a patient under surveillance of urologist and oncologist. Histomorphology diagnosis revealed squamous cell carcinoma ICD-O CODE 8070/3 grade G1 (well differentiated) of the foreskin. Prognostic factors are given below:

- $\quad$ Cancer size 3.ox3.oxo.5 
- Depth of invasion $0.5 \mathrm{~cm}(5 \mathrm{~mm})$

- Invasion in the blood vessels - Not revealed

- $\quad$ Prognostic index $=1(\mathrm{LP})+1(\mathrm{G} 1)=2$ (low)

- $\quad$ TNM value - p T2, NX, MX

Case2

61 Year old male patient M.T. visited hospital with the complaint of having an irregular tissue lesion on the glans of penis as a single conglomerate. Patient was consulted to venerologist and he completed 4 week course of retarpen. Later, he was diagnosed with non-confirmatory syphilis. MRI was conducted before and after treating syphilis. During the first MRI examination of the lymph nodules located near the hip blood vessel where not enlarged. There was also no change in the structure of bony pelvis. Inguinal lymph nodules appeared $2.2 \mathrm{~cm}$. Partial glans amputation and extended inguinal hip lymphadenectomy(Duchenne bilateral surgery) were performed. Histology revealed squamous epithelial cell carcinoma with invasion in fatty tissue and left hip metastatic damage L/G.

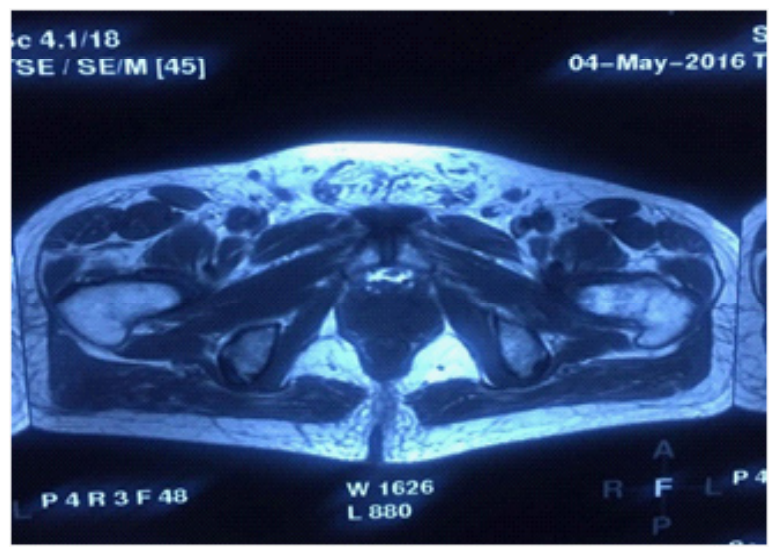

Picture 4

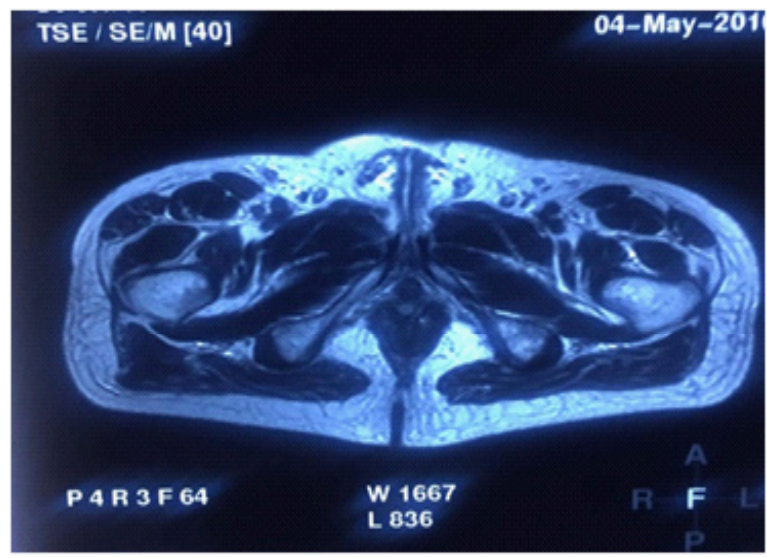

Picture 5

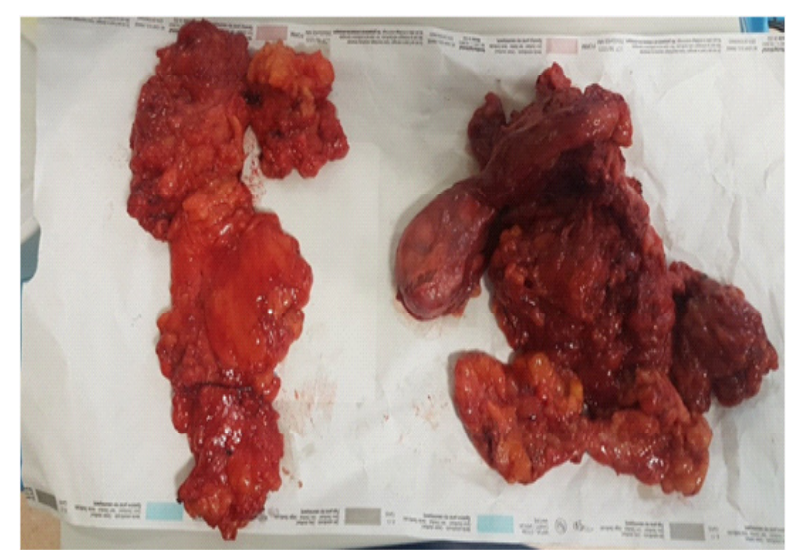

Picture 6

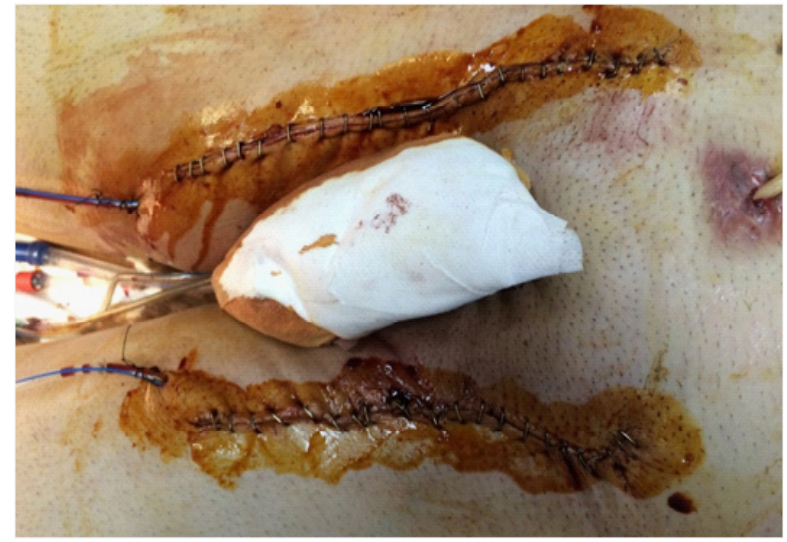

Picture 7

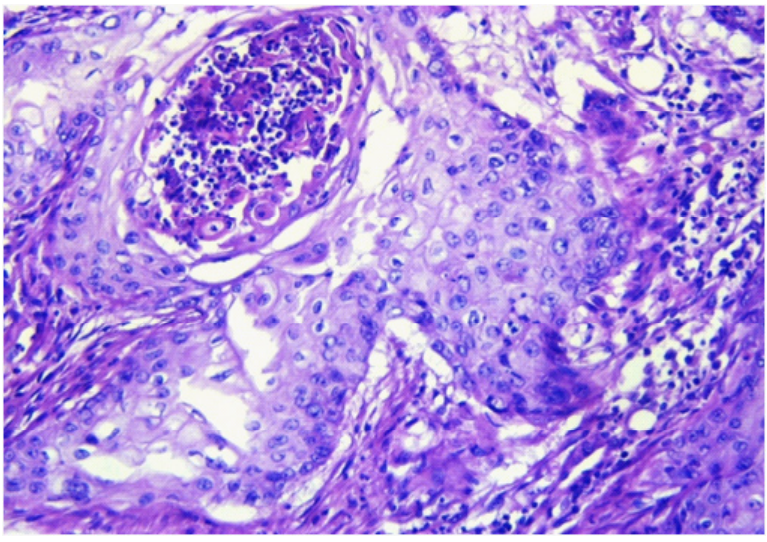

Picture 8

\section{Counclusion}

Syphilis was considered a major cause of penile cancer. The possible role of syphilis was discarded without much debate with the detection of certain of human papillomaviruses centrally involved in the etiology of penile cancer. Therefore, in both cases, syphilis was a significant risk factor for the development of penile cancer. In diagnoses process, it is very important to be correctly evaluates location of primary lesion 
and anatomy-morphology database, as well as regional(inguinal and hip) lymph nodes statements. That is why when we suspect penile cancer it is necessary to make MRI or CT of primary regional lymph nodes. Histomorphological characteristics of penile cancer is important for conformation of diagnoses. If oncology functional status allow initiate anti-luetic treatment0, to esteem regional lymph nodes in post therapeutic statement can rule out the decision of extended lymphadenectomy. When we have two pathologies, treatment strategy is multidisciplinary by the decision of consilium (Urologist, dermato-venerologist, oncologist and radiologist) and the advantage is given to the form of syphilis activity, as well as to the issue regarding distribution of oncological disease. We followed up patient's conditions. They are under surveillance of oncourologist as well as MRI and general urinalys, which are done on repetitive manner.

\section{REFERENCES}

[1] Bleeker MC, Heideman DA, Snijders PJ, et al. Penile cancer: epidemiology, pathogenesis and prevention. World J Urol. 2009;

[2] Morris BJ, Gray RH, Castellsague X, et al. The strong protective effect of circumcision against cancer of the penis. Adv Urol. 2011;

[3] Pettaway CA, Lance RS, Davis JW. Tumors of the penis. In: Wein AJ, Kavoussi LR, Novick AC,
Partin AW, Peters CA, editors. Campbell-Walsh Urology. 10th ed. Philadelphia: Elsevier Health Sciences; 2011

[4] Edge SB, Byrd DR, Compton CC, editors. AJCC Cancer Staging Manual. 7th edition. France: Springer; 2010.

[5] Lam W, Alnajjar HM, La-Touche S, et al. Dynamic sentinel lymph node biopsy in patients with invasive squamous cell carcinoma of the penis: a prospective study of the long-term outcome of 500 inguinal basins assessed at a single institution. Eur Urol. 2013;

[6] Wan Q, Li ZY, Shen ZJ, Zhu XW, Zhang ZG, et al. (2006) penilesquamouscarcinomaincircumcised patients: a report 17 cases. Zhonghua Nan Ke Xue 12:1108-1109.

[7] A, Kim T, Giuliano A, et al. Implications for human papillomavirus in penile cancer. Urol Oncol 2014;

[8] Sow Y, Thiam A, Fall B, Coulibali M, Sarr A, et al. (2012) Cancer du pénis au Sénégal: Aspects cliniques et thérapeutiques. Andrologie 22: 102107.

[9] Rigaud J, Avancès C, Camparo P, Culine S, Durand X, et al. (2010) Les membres du CCAFU Recommandations en Onco-Urologie Tumeurs malignes du pénis. Urology Suppl4: 279-289.

Citation: Vladimer Papava, et al. Penile Cancer and Syphilis: Report of Two Cases. Archives of Urology. 2018; 1(1): 1-4.

Copyright: (C) 2018 Vladimer Papava, et al. This is an open access article distributed under the Creative Commons Attribution License, which permits unrestricted use, distribution, and reproduction in any medium, provided the original work is properly cited. 